\title{
FERTIRRIGAÇÃO NITROGENADA E NÍVEIS DE HIDROGEL PARA A CULTURA DA ALFACE IRRIGADA POR GOTEJAMENTO
}

Gabriel Queiroz de Oliveira ${ }^{1}$, Guilherme Augusto Biscaro² ${ }^{2}$ Leandro Henrique Jung ${ }^{3}$, Érica de Oliveira Araújo ${ }^{4}$, Paulo Sergio Vieira Filho ${ }^{5}$

\section{RESUMO}

A busca pelo um sistema de produção que otimize a eficiência produtiva da planta é tema de várias pesquisas, logo, é importante o estudo sobre a aplicação de nitrogênio e água no solo para aproveitamento da cultura da alface. O objetivo desse trabalho foi avaliar a cultura da alface, tipo "Mimosa Roxa", sobre influência de doses de nitrogênio e hidrogel em Latossolo Vermelho distroférrico. O trabalho foi realizado na Universidade Federal da Grande Dourados, em Dourados, MS. O delineamento experimental foi em blocos casualizados com parcelas subdivididas com três blocos. As parcelas foram compostas por seis doses de nitrogênio aplicadas na água de irrigação (zero, 40, 80, 120, 160 e 200 $\mathrm{kg} \mathrm{ha}^{-1}$ de N) e, as subparcelas foram compostas por cinco níveis de hidrogel aplicados no solo (zero, 50, 100, 150 e $200 \mathrm{~g} \mathrm{~m}^{-2}$ ). O transplante das mudas para o canteiro ocorreu no dia 15 de julho de 2013 e a colheita foi realizada aos 53 dias após o transplante. Durante o ciclo da alface, o manejo de irrigação foi baseado no monitoramento hídrico do solo, utilizando o sensor de umidade volumétrica do solo Hidrofarm. Foram avaliados: o número de folhas, diâmetro médio da parte aérea, diâmetro do caule, massa fresca, e seca da parte aérea e a eficiência no uso da água. Conclui-se que as doses de hidrogel influenciam linearmente a eficiência no uso da água pela alface. A massa fresca e seca da parte aérea obteve seu máximo valor com doses de nitrogênio de 123,04 e 118,51 kg ha ${ }^{-1}$, respectivamente.

Palavras-chave: Lactuca sativa; produtividade; eficiência no uso da água; umidade do solo.

\section{ABSTRACT \\ NITROGEN FERTIGATION AND HYDROGEL LEVELS FOR CULTIVATION OF LETTUCE SUBMITTED TO DRIP IRRIGATION}

The search for a production system that optimizes the productive efficiency of plants is the subject of several studies, thus it is important to study the application of nitrogen and water to the soil for production of lettuce. The aim was to evaluate the lettuce crop, type "Mimosa Roxa", submitted to the influence of nitrogen and hydrogel in Latossolo Vermelho distroférrico (Oxisol). The study was conducted at the Universidade Federal da Grande Dourados (Federal University of Dourados Great), in Dourados, MS. A completely randomized split plot delineation was used with three blocks. Each plot consisted of six doses of nitrogen applied to the irrigation water (zero, 40, 80, 120,160 and $200 \mathrm{~kg} \mathrm{ha}^{-1}$ of $\mathrm{N}$ ), and the subplots consisted of five levels of hydrogel applied to the soil (zero, 50, 100, 150 and $200 \mathrm{~g} \mathrm{~m}^{-2}$ ). Transplantation of seedlings to the garden occurred on July 15, 2013 and plants were harvested 53 days after transplanting. During the lettuce cycle, irrigation management was based on monitoring the water status of the soil using a soil moisture sensor. The variables evaluated were: number of leaves, diameter of shoot, stem diameter, fresh and dry mass of shoots and efficiency in water use. For data analysis, the analysis of variance and regression evaluations were conducted. It was concluded that doses of hydrogel linearly influence the efficiency of water use by lettuce. The fresh and dry weight of the shoots presented maximum values with the nitrogen doses of 123.04 and $118.51 \mathrm{~kg} \mathrm{ha}^{-1}$, respectively.

Keywords: Lactuca sativa, yield, water use efficiency, soil moisture.

\section{Recebido para publicação em 02/03/2014. Aprovado em 23/06/2014.}

1 - Eng. Agrônomo, Doutorando em Agronomia, FCA/UFGD, Dourados, MS. gabrielqo@hotmail.com

2 - Eng. Agrícola, Professor Adjunto, FCA/UFGD, Dourados, MS. guilhermebiscaro@ufgd.edu.br

3 - Eng. Agrônomo, Doutorando em Agronomia, FCA/UFGD, Dourados, MS. ljung61@hotmail.com

4 - Eng. Agrônoma, Doutoranda em Agronomia, FCA/UFGD, Dourados, MS. ericabb25@hotmail.com

5 - Estudante de Engenharia Agrícola, FCA/UFGD, Dourados, MS. paulo_svf@hotmail.com

456 REVENG

456-465p. ENGENHARIA NA AGRICULTURA, VIÇOSA - MG, V.22 N.5, SETEMBRO / OUTUBRO 2014 


\section{INTRODUÇÃO}

Aalface (Lactucasativa L.)éuma planta herbácea, pertencente à família Asteraceae, sendo utilizada na alimentação humana há aproximadamente 2500 anos e, dentre as folhosas, é a mais consumida pelos brasileiros, sendo a sexta hortaliça em importância econômica (SANTANA et al., 2009). A participação de Mato Grosso do Sul na produção de alface obteve uma produção de 1.935 toneladas, correspondendo a 1,3\% do total das hortaliças produzida no Estado (CEASA, 2010).

O nitrogênio é um macronutriente essencial, pois participa da formação de proteínas, aminoácidos e de outros compostos importantes no metabolismo das plantas. Sua ausência bloqueia a síntese de citocinina, hormônio responsável pelo crescimento das plantas, causando redução do seu tamanho e, consequentemente, redução da produção (OLIVEIRA et al., 2003). Pelo fato da cultura ser composta basicamente de folhas, a mesma responde bem ao fornecimento de nitrogênio, nutriente que requer um manejo especial quanto à adubação, por ser de fácil lixiviação e pelo fato da alface absorver maior quantidade na fase final do ciclo (RESENDE et al., 2012). Bastos et al. (2008), destacaram que pesquisas regionais visando determinar as doses de nitrogênio são de grande importância para o agricultor racionalizar os custos de produção e aumentar a rentabilidade.

A alface é uma cultura exigente em água, sendo o manejo adequado da irrigação importante não apenas por suprir as necessidades hídricas das plantas, mas também por minimizar problemas com doenças e lixiviação de nutrientes, e com gastos desnecessários com água (KOETZ et al., 2006). Segundo Souza et al. (2005), entre os sistemas de irrigação, o gotejamento possui as melhores condições de proporcionar alto controle e alta uniformidade na aplicação de água e fertilizantes, sendo esta aplicação de fertilizante juntamente com a água denominada técnica de fertirrigação. Dentre as tecnologias empregadas, a fertirrigação aplica fertilizantes através da água de irrigação no sistema de gotejamento ou microaspersão, onde, se bem manejada, favorece uma boa aproximação do ritmo de absorção de água e de nutrientes pela planta (VILLAS BOAS et al., 2000).
O uso de condicionadores sintéticos (hidrogel) tem contribuído para aumentar a capacidade de retenção de água no solo, reduzindo a frequência de irrigação e permitindo a utilização mais efetiva dos recursos solo e água, contribuindo para melhorar o rendimento das culturas (WANG; BOOGHER, 1987). Os hidrogeis são produtos naturais ou sintéticos valorizados pela sua habilidade em absorver e armazenar água, podendo ser granulados e quebradiços quando secos, se tornando macios e elásticos depois de expandidos na água (MORAES et al., 2001).

Segundo Lamaud et al. (1996), a eficiência de uso da água (EUA) representa a capacidade que a vegetação possui em assimilar carbono, enquanto limita as perdas de água, através dos estômatos. Albuquerque Filho et al. (2009) salientaram que, para a cultura do coentro, a eficiência do uso da água, o rendimento de massa verde, o rendimento de massa seca e o número de plantas, aumentaram linearmente com a elevação das doses do polímero quando se fixa a menor lâmina proveniente de $60 \%$ da evapotranspiração de referência. Segundo Oliveira et al. (2004), o uso do hidrogel contribui para aumentar a retenção de água nos solos de texturas franco-argiloarenosa e argilosa, até a tensão de $100 \mathrm{kPa}$.

Dessa forma o objetivo deste trabalho foi avaliar a influência de doses de nitrogênio aplicadas via fertirrigação e níveis de hidrogel em Latossolo Vermelho distroférrico, quanto à produção e a eficiência no uso da água da cultura da alface "Mimosa Roxa" irrigada por gotejamento.

\section{MATERIAL E MÉTODOS}

O experimento foi conduzido no período de maio a agosto de 2013 na área Experimental de Irrigação e Drenagem da Faculdade de Ciências Agrárias (FCA) da Universidade Federal da Grande Dourados (UFGD), em Dourados (MS), situada nas coordenadas de $22^{\circ} 11^{\prime} \mathrm{S}$ e $54^{\circ} 56^{\prime} \mathrm{W}$, com altitude de $446 \mathrm{~m}$. O clima é do tipo Cwa, mesotérmico úmido, e a precipitação média anual é de $1500 \mathrm{~mm}$ com temperatura média anual de $22{ }^{\circ} \mathrm{C}$. O solo da área experimental é classificado como Latossolo Vermelho distroférrico (EMBRAPA, 2009), de textura muito argilosa. Na Figura 1 é apresentada a temperatura média e umidade relativa do ar durante o período de condução da pesquisa. 


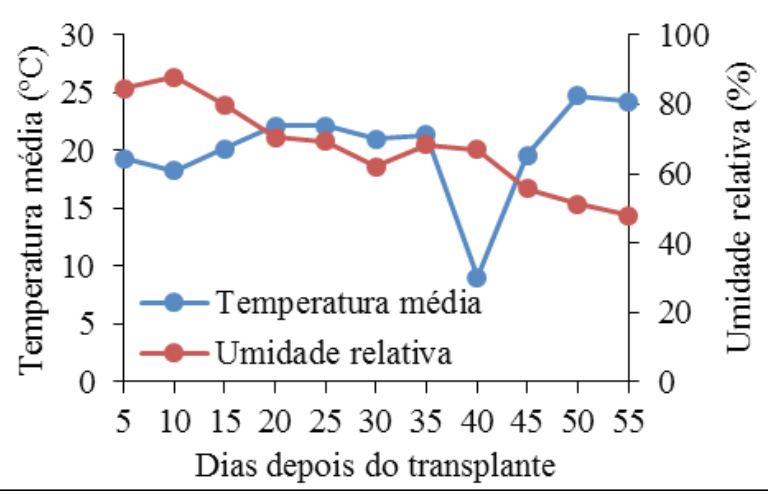

Figura 1. Temperatura média e umidade relativa do ar durante o período de desenvolvimento da alface "Mimosa Roxa". Dourados-MS, 2013.

As mudas de alface foram produzidas em estufa plástica com bandejas de isopor de 200 células. Estas foram preenchidas com substratos comercial para produção de mudas, sendo a alface "Mimosa Roxa" (Salad Bowl, Topseed $\AA$ ) semeada no dia 22 de maio de 2013. Após 9 dias foi realizado o desbaste deixando uma muda em cada célula.

$\mathrm{Na}$ área experimental foram coletadas amostras de solo na profundidade de 0,00-0,20 m para análises química e granulométrica (Quadro 1).

Com base nos resultados da análise de solo e de acordo com Alvarez et al. (1999), foi realizada a calagem e adubação de base. A aplicação de calcário foi realizada 45 dias antes do transplante (DAT), na quantidade equivalente a $2,5 \mathrm{Mg}$ ha- 1 , distribuindo proporcionalmente no canteiro para elevar a saturação de bases a 70\%. Para adubação de base, foram aplicados $80 \mathrm{~kg}$ ha-1 de fósforo, cuja fonte foi o superfosfato simples (18\% de P2O5) e $100 \mathrm{~kg}$ ha-1 de potássio, por meio do cloreto de potássio (60\% de $\mathrm{K} 2 \mathrm{O}$ ), sendo $60 \mathrm{~kg}$ ha-1 desses aplicados em cobertura, fornecidos através de quatro fertirrigações, sendo aos 10, 20, 30 e 40 DAT em todas as parcelas.
O delineamento experimental foi em blocos casualizados com parcelas subdivididas, constituído por seis doses de nitrogênio na parcela (zero, 40, 80, 120, 160 e $200 \mathrm{~kg}$ ha-1) com ureia como fonte de nitrogênio e, cinco níveis de hidrogel na subparcela (zero, 50, 100, 150 e $200 \mathrm{~g}$ $\mathrm{m}-2$ ) com três blocos. Para a injeção do nitrogênio na água de irrigação, foi utilizado um injetor por indução diferencial de pressão, tipo "Vaquinha". Foi utilizado o hidrogel da marca Hidroterragel ${ }^{\circledR}$ adicionado no canteiro nas proporções de cada subparcela e, através de enxada, incorporado até a profundidade de $0,20 \mathrm{~m}$. As doses referentes ao tratamento do fator nitrogênio foram aplicadas em quatro períodos: 10, 20, 30 e 40 dias depois do transplante (DDT).

A alface foi transplantada no dia 15 de junho de 2013 para o campo. O método de irrigação utilizado foi o localizado, cujo sistema foi por gotejamento, com mangueira gotejadora da marca Petrodrip ${ }^{\circledR}$, modelo Manari, com espaçamento de 0,20 m entre emissores, vazão de $1,5 \mathrm{~L} \mathrm{~h}-1$, com pressão de serviço de 97,8 kPa, sendo instalada uma linha de irrigação para cada linha de alface, espaçada em $0,30 \mathrm{~m}$, onde cada planta ocupava área de $0,06 \mathrm{~m} 2$.

$\mathrm{O}$ modelo matemático empregado na determinação da curva de retenção de água no solo foi o de van Genutchen (1980), por meio da Equação 1.

$\theta \mathrm{a}=\theta \mathrm{r}+\frac{(\theta \mathrm{s}-\theta \mathrm{r})}{\left[1+(\alpha|\Psi \mathrm{m}|)^{\mathrm{n}}\right]^{\mathrm{m}}}$

em que,

$\theta_{\mathrm{a}}$ - umidade atual $\left(\mathrm{m}^{3} \mathrm{~m}^{-3}\right)$

$\theta_{\mathrm{r}}$ - umidade residual $\left(\mathrm{m}^{3} \mathrm{~m}^{-3}\right)$;

$\theta_{\mathrm{s}}$ - umidade na saturação $\left(\mathrm{m}^{3} \mathrm{~m}^{-3}\right)$;

$\psi_{\mathrm{m}}$ - potencial mátrico (cm c.a.); e

$\alpha, \mathrm{m}, \mathrm{n}-$ coeficientes do modelo descritos no Quadro 2.

Quadro 1. Análise química e textural do solo do Latossolo Vermelho distroférrico na profundidade de 0,000,20 m. Dourados-MS, 2013

\begin{tabular}{|c|c|c|c|c|c|c|c|c|c|c|c|}
\hline \multirow{2}{*}{$\begin{array}{c}\mathrm{pH} \\
\mathrm{CaCl}_{2}\end{array}$} & \multirow{2}{*}{$\begin{array}{c}P \\
\mathrm{mg} \mathrm{dm}^{-3}\end{array}$} & \multirow[t]{2}{*}{ K } & \multirow[t]{2}{*}{$\mathrm{Al}$} & \multirow[t]{2}{*}{$\mathrm{Ca}$} & \multirow[t]{2}{*}{$\mathrm{Mg}$} & \multirow[t]{2}{*}{$\mathrm{H}+\mathrm{Al}$} & \multirow[t]{2}{*}{ SB } & \multirow[t]{2}{*}{ CTC } & \multicolumn{3}{|c|}{ Textura $\left(\mathrm{g} \mathrm{kg}^{-1}\right)$} \\
\hline & & & & & & & & & Areia & Silte & Argila \\
\hline 4,90 & 39,60 & 0,45 & 0,09 & 6,08 & 1,73 & 5,76 & 8,26 & 14,02 & 175 & 150 & 675 \\
\hline
\end{tabular}


Quadro 2. Umidade volumétrica, parâmetros do modelo de van Genuchten (1980) e o coeficiente de determinação $\left(\mathrm{R}^{2}\right)$ entre o medido e o estimado pelo modelo. Dourados-MS, 2013

\begin{tabular}{ccccccccc}
\hline Profundidade & \multicolumn{3}{c}{ Umidade $\left(\mathrm{m}^{3} \mathrm{~m}^{-3}\right)$} & \multicolumn{3}{c}{ Parâmetros de van Genuchten } & \multicolumn{2}{c}{ Ajuste } \\
\hline \multirow{2}{*}{$0,00-0,20 \mathrm{~m}$} & $\theta \mathrm{s}$ & $\theta \mathrm{cc}$ & $\theta \mathrm{pmp}$ & $\theta \mathrm{r}$ & $\alpha$ & $\mathrm{m}$ & $\mathrm{n}$ & $\mathrm{R}^{2}$ \\
\cline { 2 - 10 } & 0,5804 & 0,3896 & 0,2133 & 0,2110 & 0,0546 & 0,0443 & 11,3606 & 0,989 \\
\hline
\end{tabular}

O manejo de irrigação foi realizado com base no estado hídrico do solo, utilizando o sensor de umidade volumétrica do solo "Hidrofarm", que determina a teor de água através da impedância do solo a alta frequência, no qual a leitura era realizada as 10:00 horas de cada dia. Sendo assim, a irrigação era efetuada diariamente, conforme a média do teor de água dos três sensores por tratamento.

Como referência para o cálculo da lâmina de irrigação, determinou-se a capacidade de água disponível (CAD) (Equação 2) e como critério para aplicação de água para a alface a água facilmente disponível para irrigação (AFD), conforme Bernardo et al. (2008), pois a porcentagem da área molhada foi equivalente a $100 \%$ (Equação 3). Utilizou-se também como monitoramento de ocorrência de déficit hídrico no solo a determinação da reserva de água no solo (RAD), conforme Equação 4.

$$
\mathrm{CAD}=\left(\theta_{\mathrm{es}}-\theta_{\mathrm{pmp}}\right) \mathrm{Z}
$$

$\mathrm{AFD}=\left(\theta_{w}-\theta_{\mathrm{a}}\right) \mathrm{Z}$

$\mathrm{RAD}=\mathrm{CAD}-\mathrm{AFD}$

em que,

$\theta_{\text {cc }}$ - umidade do solo na capacidade de campo $\left(0,3896 \mathrm{~m}^{3} \mathrm{~m}^{-3}\right.$; potencial mátrico de $\left.-10 \mathrm{kPa}\right)$;

$\theta_{\text {cc }}$ - umidade do solo no ponto de murcha permanente $\left(0,2133 \mathrm{~m}^{3} \mathrm{~m}^{-3}\right.$; potencial mátrico de $-1500 \mathrm{kPa})$;

$\theta_{\mathrm{a}}$ - umidade atual $\left(\mathrm{m}^{3} \mathrm{~m}^{-3}\right) ; \mathrm{e}$

$\mathrm{Z}$ - profundidade do sistema radicular $(\mathrm{mm})$.

Cada subparcela continham 30 plantas, onde foram avaliadas oito plantas centrais. A colheita foi realizada aos 53 DDT. Foram avaliados: o diâmetro médio da parte aérea $(\mathrm{cm})$, diâmetro do caule $(\mathrm{mm})$, número de folhas, massa fresca, e seca da parte aérea $\left(\mathrm{g} \mathrm{planta}^{-1}\right)$ e a eficiência no uso da água $\left(\mathrm{g} \mathrm{mm}^{-1}\right.$ planta $\left.^{-1}\right)$ da alface "Mimosa Roxa".

Os parâmetros avaliados foram submetidos à análise de variância e, quando os mesmos foram significativos no nível de $5 \%$ de probabilidade, os dados foram interpretados através de modelos de regressão linear e quadrática.

\section{RESULTADOS E DISCUSSÃO}

Verifica-se no Quadro 3 o resumo da análise de variância referente aos parâmetros da alface, no qual todos os parâmetros foram influenciados pelas doses de nitrogênio aplicados em fertirrigação. A análise de variância mostrou que houve influência das doses de hidrogel somente para o parâmetro eficiência no uso da água (EUA) e que não houve interação entre os tratamentos com manejos de doses de nitrogênio e hidrogel para todos os parâmetros avaliados da alface "Mimosa Roxa" (Quadro 3).

Diante dos níveis de hidrogel aplicados no solo, a lâmina de irrigação obteve diferentes valores. As lâminas totais aplicadas (precipitação + irrigação) durante o período de experimento foram de 841,7; 801,8; 752,0; 743,7 e 739,7 mm, em relação às doses de hidrogel de zero, 50, 100, 150 e $200 \mathrm{~g} \mathrm{~m}^{-2}$, respectivamente, sendo que a precipitação pluviométrica correspondeu a 114,0 $\mathrm{mm}$. Com a aplicação de hidrogel no solo houve redução da lâmina de irrigação em comparação ao tratamento sem hidrogel, na qual a dose com $200 \mathrm{~g} \mathrm{~m}^{-2}$ obteve economia de água na ordem de 14,9\% (Quadro 4). Através da leitura do sensor de umidade volumétrica, verificou-se que, nos tratamentos com hidrogel, houve maior retenção de água em Latossolo Vermelho distroférrico, ocasionando menor lâmina média. Bandeira et al. (2011), verificaram que no manejo da irrigação na cultura da alface, monitorando o estado hídrico do 
Quadro 3. Quadrado médio dos parâmetros diâmetro médio da parte aérea (DPA), diâmetro do caule (DC), número de folhas (NF), massa fresca (MF), e seca (MS) da parte aérea e a eficiência no uso da água (EUA) da alface "Mimosa Roxa" em função das doses de hidrogel e nitrogênio. Dourados-MS, 2013

\begin{tabular}{lccccccc}
\hline \multicolumn{1}{c}{ FV } & GL & DPA & DC & NF & MF & MS & EUA \\
\hline Bloco & 2 & 0,748 & 160,158 & 23,837 & 75,214 & 9,631 & 0,00019 \\
Nitrogênio (N) & 5 & $332,158^{* * *}$ & $47,776^{* *}$ & $87,333^{* *}$ & $14415,3^{* *}$ & $485,018^{* *}$ & $0,0363^{* * *}$ \\
Resíduo & 10 & 10,392 & 5,843 & 6,013 & 64,760 & 17,186 & 0,00017 \\
\hline CV $(\%)$ & - & 12,61 & 14,94 & 16,44 & 6,18 & 19,84 & 6,35 \\
\hline Hidrogel (H) & 4 & $7,047^{\text {ns }}$ & $9,077^{\text {ns }}$ & $1,508^{\text {ns }}$ & $66,512^{\text {ns }}$ & $6,595^{\text {ns }}$ & $0,00480^{* * *}$ \\
N x H & 20 & $10,487^{\text {ns }}$ & $5,735^{\text {ns }}$ & $2,830^{\text {ns }}$ & $56,694^{\text {ns }}$ & $3,261^{\text {ns }}$ & $0,00015^{\text {ns }}$ \\
Resíduo & 48 & 15,43 & 7,459 & 8,482 & 68,448 & 10,557 & 0,00018 \\
\hline CV(\%) & - & 15,37 & 16,88 & 19,52 & 6,35 & 15,55 & 6,50 \\
\hline
\end{tabular}

${ }^{\mathrm{ns}}$ não significativo; $* *, * * *$ significativo a $1 \%$ e $0,01 \%$ de probabilidade pelo teste $\mathrm{F}$ respectivamente.

Quadro 4. Lâmina de irrigação, número de irrigação e turno de rega em função dos níveis de hidrogel aplicados em Latossolo Vermelho distroférrico cultivado com alface "Mimosa Roxa". Dourados-MS, 2013

\begin{tabular}{ccccc}
\hline $\begin{array}{c}\text { Hidrogel } \\
\left(\mathrm{g} \mathrm{m}^{-2}\right)\end{array}$ & $\begin{array}{c}\text { Lâmina média } \\
(\mathrm{mm})\end{array}$ & Lâmina total $(\mathrm{mm})$ & $\begin{array}{c}\text { Diferença } \\
\text { percentual }\end{array}$ & $\begin{array}{c}\text { Precipitação total }^{1} \\
(\mathrm{~mm})\end{array}$ \\
\hline Zero & 13,2 & 697,7 & - & 841,7 \\
50 & 12,4 & 657,8 & 5,7 & 801,8 \\
100 & 11,5 & 608,0 & 12,9 & 752,0 \\
150 & 11,3 & 599,7 & 14,0 & 743,7 \\
200 & 11,2 & 595,7 & 14,9 & 739,7 \\
\hline
\end{tabular}

${ }^{1}$ Precipitação pluviométrica + irrigação

solo com tensiômetros ao potencial matricial de $-30 \mathrm{kPa}$, a lâmina total de irrigação correspondeu a $280,0 \mathrm{~mm}$, ou seja, valor bastante baixo ao encontrado no presente trabalho.

De acordo com Cardoso e Klar (2009), a alface "Mimosa" consome cerca de 170,0 mm, mesmo em condições de umidade do solo próximo a capacidade de campo no momento de irrigar e atribuíram esse consumo às características morfológicas, como folhas rugosas e finas, e também por apresentar maior superfície de contato com atmosfera.

Em relação ao presente estudo, nota-se que existe uma discrepância em relação ao consumo de água pela cultura da alface no que consta na literatura. $\mathrm{O}$ sensor de umidade do solo utilizado no experimento (Hidrofarm) pode ter subestimado a umidade do solo e com isso propiciando maior reposição de água. Segundo Gomes et al. (2013), em Latossolo Vermelho distroférrico é indicado que o sensor de umidade volumétrica "Hidrofarm" seja ajustado através de equação que descreve sua relação com a umidade determinada com o método padrão de estufa e salientaram que, devido ao aparelho apresentar o sensor em forma de "régua", dificulta um pouco a sua completa inserção quando o solo apresenta baixa umidade em sua camada 
superficial. A lâmina de irrigação no presente estudo demonstrou que houve excesso de água aplicada, uma vez que a lâmina ideal, segundo Gonçalves et al. (2005), é de 167,0 mm, ou seja, foi aplicada aproximadamente quatro vezes o consumo de água.

A distribuição da chuva e a variação da lâmina de irrigação em cada tratamento de dose de hidrogel, no decorrer do período avaliado, evidencia que sem hidrogel a lâmina de irrigação foi superior aos tratamentos com hidrogel (Figura 2).

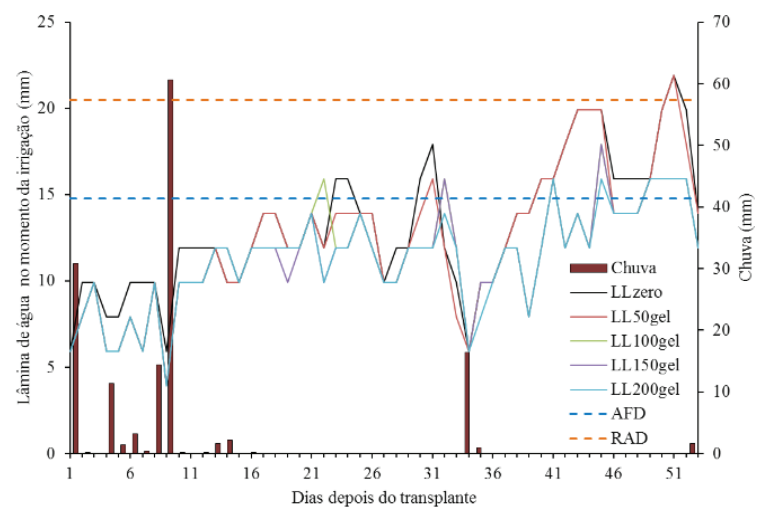

Figura 2. Variação da lâmina de irrigação, água facilmente disponível (AFD) e reserva de água disponível (RAD) e de chuva recebida pelas plantas de alface "Mimosa Roxa". LL zero, LL 50 gel, LL 100 gel, LL 150 gel e LL 200 gel.

Durante grande parte do desenvolvimento das plantas de alface, observou-se que, nos tratamentos com doses de hidrogel de 150 e $200 \mathrm{~g}$ $\mathrm{m}^{-2}$, as lâminas de irrigação permaneceram abaixo da água facilmente disponível. Provavelmente, porque com as doses mais elevadas de hidrogel podem ter ocasionado maior retenção de água no solo, diminuindo as perdas por percolação, de maneira que esse polímero propicia maior umidade volumétrica e, com isso, menor reposição de lâmina aplicada melhorando a eficiência no uso da água.

Segundo Oliveira et al. (2004), de modo geral, o hidrogel propicia maior eficiente na retenção de água para o solo argiloso e salientaram que o hidrogel usado na concentração de $20 \mathrm{~g} \mathrm{~kg}^{-1}$ de solo aumentou a umidade, no potencial matricial de $-30 \mathrm{kPa}$, em $37 \%$ para o solo argiloso. No entanto, Prevedello e Loyola (2007), observaram que o hidrogel aplicado em Latossolo Vermelho de textura argilosa não contribui para diminuição da taxa de infiltração de água com a concentração de hidrogel equivalente a 0,8 e $1,6 \mathrm{~kg} \mathrm{~m}^{-2}$. Contudo, quando comparado com meio arenoso a infiltração pode ser reduzida em até 13 vezes.

As doses de hidrogel influenciaram apenas o parâmetro de eficiência no uso da água da alface "Mimosa Roxa" cultivado em Latossolo Vermelho distroférrico. Apesar das doses de hidrogel não terem influenciado a massa fresca média por planta, as mesmas permitiram que houvesse aumento do teor de água no solo no momento da irrigação, quando comparado com a dose zero, talvez devido à baixa retenção de água no solo. Sendo assim, houve aumento linear da eficiência no uso da água pela cultura da alface com o aumento das doses de hidrogel (Figura 3A). Esse aumento obteve uma eficiência no uso da água na ordem de $10,1 \%$, $17,8 \%, 17,5 \%$ e $18,3 \%$ para as doses de 50,100 , 150 e $200 \mathrm{~g} \mathrm{~m}^{-2}$, respectivamente, comparados com o solo sem hidrogel.
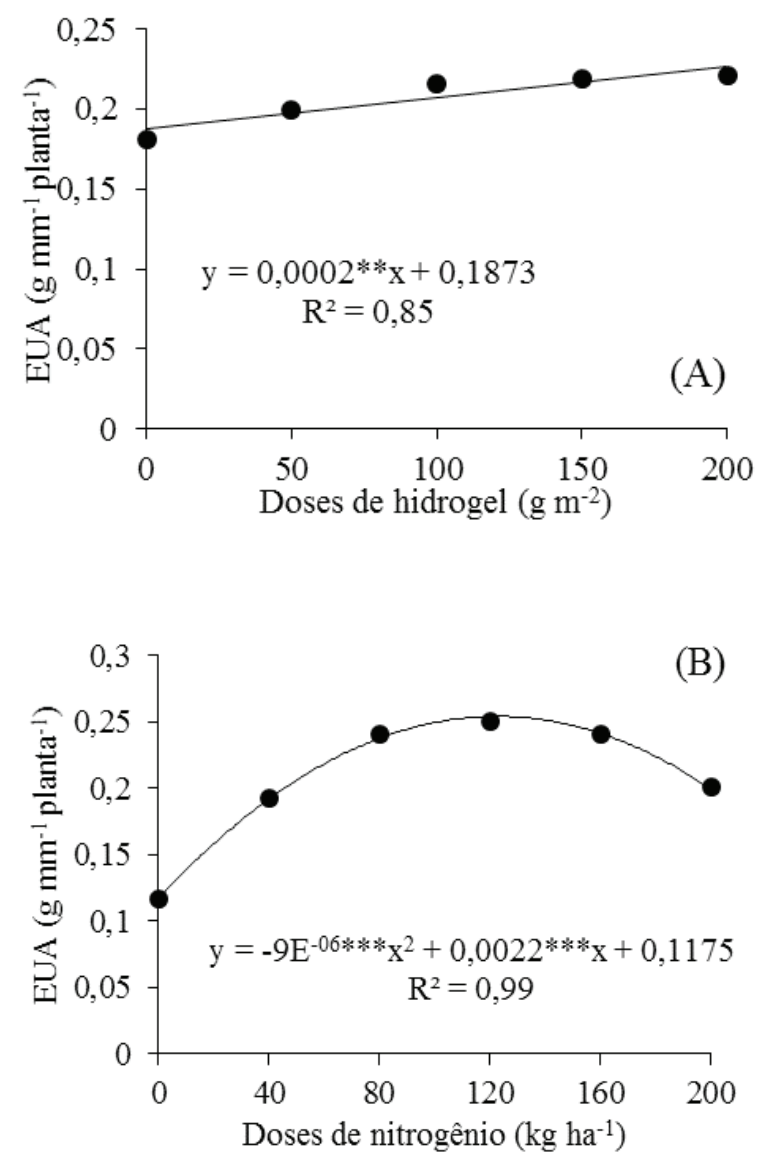

Figura 3. Eficiência no uso da água (EUA) da alface "Mimosa Roxa" em função de doses de hidrogel (A) e nitrogênio aplicados em fertirrigação (B). Dourados-MS, 2013. 
Em trabalho de Vieira et al. (2008), no qual compararam vários métodos de manejo de irrigação na cultura da alface "Americana", a tensiometria, na qual se estima a umidade volumétrica do solo indiretamente através da relação entre a tensão de água no solo, obteve-se lâmina final de 645,66 mm $\mathrm{e}$, diante desse resultado, encontraram a menor eficiência no uso da água, que foi de $0,46 \mathrm{~g} \mathrm{~mm}^{-1}$ planta $^{-1}$. Araújo et al. (2010), mostraram que é comum, no caso da alface, a eficiência do uso de água diminuir linearmente com o acréscimo da lâmina de irrigação aplicada. No entanto, o que se mostrou no presente estudo é que aplicando hidrogel no solo pode haver aumento linear da eficiência no uso da água até a dose de $200 \mathrm{~g} \mathrm{~m}^{-2}$ (Figura 3A), assim como foi demonstrado por Albuquerque Filho et al. (2009) na cultura do coentro.

Não houve interação entre os fatores nitrogênio e o hidrogel, talvez devido ao excesso de água aplicada. As doses de nitrogênio aplicadas via fertirrigação influenciaram significativamente todos os parâmetros analisados no presente trabalho. A eficiência no uso da água pela alface respondeu de maneira quadrática em função das doses de nitrogênio, no qual os coeficientes do modelo obtiveram significância de $0,01 \%$. Sendo assim, para que a alface tenha a maior eficiência no uso da água é necessário aplicar 122,22 $\mathrm{kg} \mathrm{ha}^{-1}$ de N, alcançando, dessa forma, a massa fresca de 0,252 $\mathrm{g}$ por $\mathrm{mm}$ de água aplicada por planta (Figura $3 \mathrm{~B}$ ).

$\mathrm{O}$ diâmetro de caule respondeu linearmente às doses de nitrogênio, com modelo apresentando precisão de $98 \%$. Aplicando a dose de $200 \mathrm{~kg} \mathrm{ha}^{-1}$ de $\mathrm{N}$, houve aumento de $4,42 \mathrm{~mm}$ de diâmetro em relação à alface com ausência de nitrogênio (Figura 4A). O número de folhas mostrou comportamento similar ao diâmetro de caule, como pode ser observado na Figura 4B.

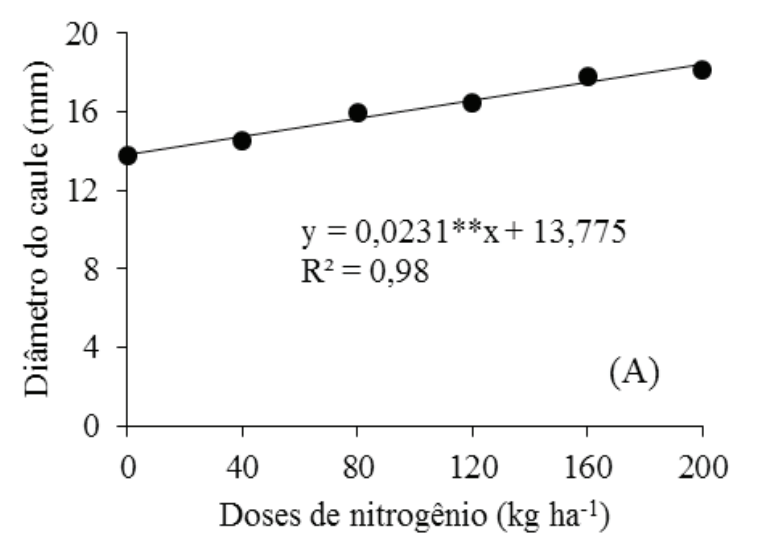

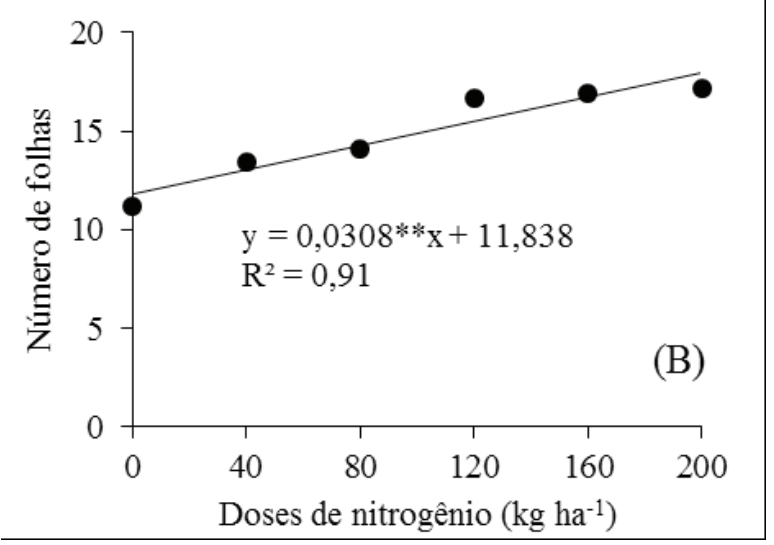

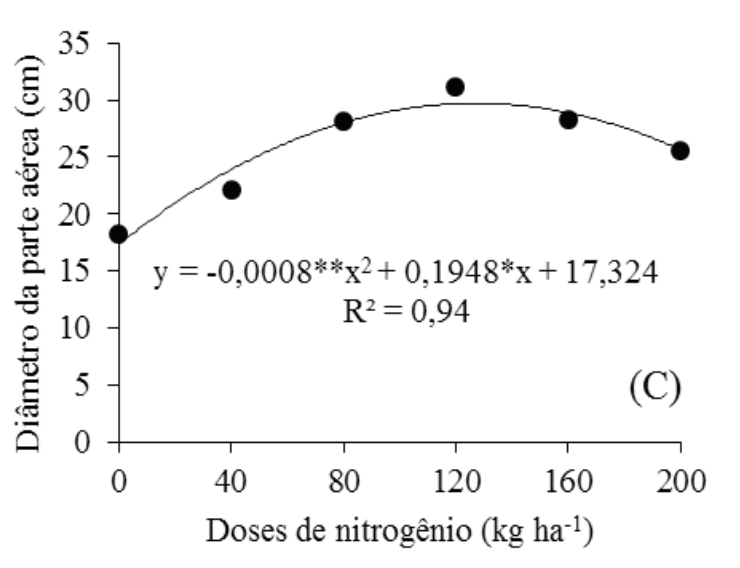

Figura 4. Diâmetro do caule (A), número de folhas (B) diâmetro da parte aérea (C) da alface "Mimosa Roxa" em função de doses de nitrogênio aplicados em fertirrigação. Dourados-MS, 2013.

Para o número de folhas, a diferença percentual da dose zero com a aplicação de $120 \mathrm{~kg} \mathrm{ha}^{-1} \mathrm{de} \mathrm{N}$ foi de $32,93 \%$ e verificou-se que, a partir da dose de nitrogênio de $120 \mathrm{~kg} \mathrm{ha}^{-1}$, houve uma variação muito pequena de número de folhas, com média 16,9 folhas e diferença entre a dose de $200 \mathrm{~kg}$ e $120 \mathrm{~kg} \mathrm{ha}^{-1}$ de 0,5 folhas, ou seja, a relação entre o aumento do número de folhas com as doses elevadas de nitrogênio foi diminuída.

Analisando o diâmetro da parte aérea, as doses de nitrogênio ajustaram-se ao modelo quadrático, no qual a dose de $121,75 \mathrm{~kg} \mathrm{ha}^{-1}$ de $\mathrm{N}$ proporcionou diâmetro máximo da parte aérea de $29,18 \mathrm{~cm}$. De acordo com a função obtida (Figura 4C), observouse incremento de $0,194 \mathrm{~cm}$ no diâmetro para cada $\mathrm{kg}$ de nitrogênio aplicado. O incremento no diâmetro da parte aérea da alface "Mimosa Roxa",

\section{REVENG 456-465p.}


comparando-se com a dose de nitrogênio que propiciou maior diâmetro da parte aérea e com a dose zero, foi de $40,63 \%$.

Tanto a massa fresca como a seca da parte aérea apresentaram comportamento quadrático. Observou-se que a massa fresca foi significativo a $1 \%$ de probabilidade e modelo matemático com $99 \%$ de precisão, sendo que a maior massa fresca foi alcançado com dose estimada em 123,04 $\mathrm{kg} \mathrm{ha}^{-1}$ de nitrogênio (Figura 5A). Como pode ser visto, houve aumento da massa fresca até a dose de 123,04 $\mathrm{kg} \mathrm{ha}^{-1}$, no qual o incremento na massa fresca, em comparação com a alface sem dose de nitrogênio, foi de $53,88 \%$, obtendo 160,15 g planta $^{-1}$.

No presente estudo, as doses de nitrogênio adicionadas via fertirrigação acima de 123,04 $\mathrm{kg} \mathrm{ha}^{-1}$ podem ter promovido um desequilíbrio nutricional, contribuindo para a redução nos valores da massa fresca da parte aérea, já que, segundo Faquin (1994), o nitrogênio em excesso pode reduzir a absorção de outros elementos essenciais, levando à deficiência nutricional, com reflexos sobre a produção.

Conforme relataram Resende et al. (2005), as doses de nitrogênio em cobertura influenciaram positivamente a massa fresca total e a circunferência da cabeça. Contudo, Resende et al. (2012), reforçaram que quando há interação entre nitrogênio e molibdênio para a massa fresca da alface "Americana" estabeleceram-se os modelos quadráticos com pontos de máxima para a produção da massa fresca. No entanto, na ausência da adubação com molibdênio a dose de $66,4 \mathrm{~kg} \mathrm{ha}^{-1}$ de $\mathrm{N}$ promoveram a maior resposta com $537,0 \mathrm{~g}$ planta $^{-1}$.

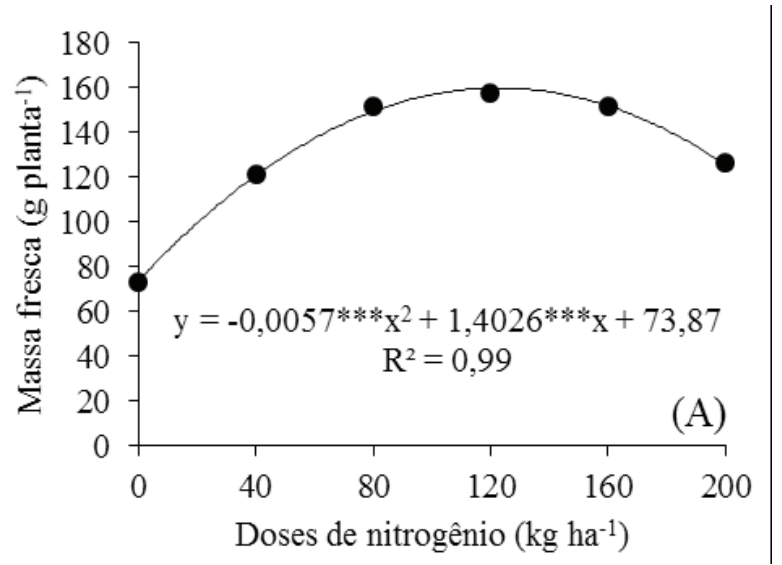

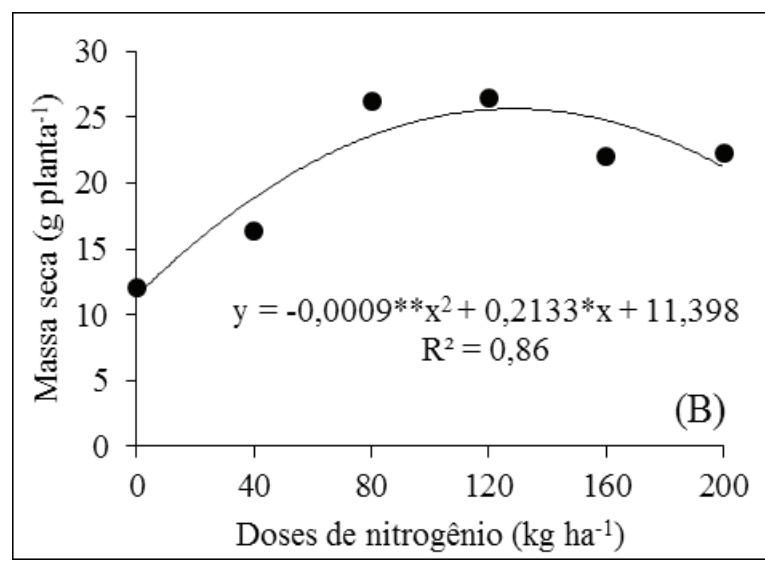

Figura 5. Massa fresca (A) e seca (B) da parte aérea da alface "Mimosa Roxa" em função de doses de nitrogênio aplicados em fertirrigação. Dourados-MS, 2013.

De acordo com o modelo de regressão quadrático apresentado na Figura 4B, a maior massa seca foi alcançada com aplicação da dose de nitrogênio de $118,51 \mathrm{~kg} \mathrm{ha}^{-1}$, obtendo massa seca de $24,03 \mathrm{~g}$ por planta. Ou seja, com a dose de $118,51 \mathrm{~kg} \mathrm{ha}^{-1}$ de $\mathrm{N}$ foi possível encontrar incremento de $12,60 \mathrm{~g}$ de massa seca quando comparado com a dose zero de $\mathrm{N}$, sendo que, cada $\mathrm{kg}$ de nitrogênio aplicado em fertirrigação proporciona aumento de $0,212 \mathrm{~g}$ até da dose de 118,51 $\mathrm{kg} \mathrm{ha}^{-1}$ de N. Segundo Araújo et al. (2011), somente adubação com esterco bovino bem curtido promovem bons resultados produtivos na alface "Crespa" e que, a partir desse pressuposto, doses de nitrogênio em cobertura utilizando a uréia como fonte em fertirrigação causa efeito negativos para o número de folhas, massa fresca e seca da parte aérea.

A importância do nitrogênio é descrita por Broadley et al. (2000), que relatam uma relação negativa entre plantas em condições normais de nitrogênio disponível e plantas deficientes, ocorrendo uma redução na massa fresca em condições de limitação do nutriente. Assim, neste contexto, foram verificados que nas plantas de alface sem a aplicação de nitrogênio todos os parâmetros produtivos são afetados de forma negativa, causando baixa eficiência no uso da água, diâmetro do caule e parte aérea, número de folhas, massa fresca e seca da parte aérea. 


\section{CONCLUSÕES}

- O uso de doses crescentes de hidrogel aumenta a eficiência do uso da água pela alface "Mimosa Roxa" em Latossolo Vermelho distroférrico;

- O diâmetro médio da parte aérea, diâmetro do caule, número de folhas, massa fresca e seca da parte aérea independem da aplicação de hidrogel no solo;

- A fertirrigação nitrogenada proporciona aumento no número de folhas e no diâmetro do caule com a dose de $200 \mathrm{~kg} \mathrm{ha}^{-1}$;

- Com a aplicação de nitrogênio via fertirrigação, a massa fresca e seca da parte aérea da alface assumem comportamento quadrático.

\section{REFERÊNCIAS BIBLIOGRÁFICAS}

ALBUQUERQUE FILHO, J.A.C.; LIMA, V.L.A.; MENEZES, D.; AZEVEDO, C.A.V.; DANTAS NETO, J.; SILVA JÚNIOR, J.G. Características vegetativas do coentro submetido a doses do polímero hidroabsorvente e lâminas de irrigação. Revista Brasileira de Engenharia Agrícola e Ambiental, Campina Grande, v.13, n.6, p.671679, 2009.

ALVAREZ, V.V.H.; NOVAIS, R.F.; BARROS, N.F.; CANTARUTTI, R.B.; LOPES, A.S. Interpretação dos resultados das análises de solo. In: RIBEIRO, A.C.; GUIMARÃES, P.T.G.; ALVAREZ, V.V.H., eds. Recomendações para o uso de corretivos e fertilizantes em Minas Gerais $\mathbf{- 5}$ aproximação. Viçosa, MG, Universidade Federal de Viçosa, 1999. p.21-25.

ARAÚJO, W.F.; SOUSA, K.T.S.; VIANA, T.V.A.; AZEVEDO, B.M.; OLIVEIRA, G.A. Rendimento e eficiência do uso da água pela alface em função da lâmina de irrigação. Revista Caatinga, Mossoró, v.23, n.4, p.115-120, 2010.

ARAÚJO, W.F.; SOUSA, K.T.S.; VIANA, T.V.A.; AZEVEDO, B.M.; BARROS, M.M.; MARCOLINO, E. Resposta da alface a adubação nitrogenada. Revista Agro@mbiente, Boa Vista, v.5, n.1, p.12-17, 2011.
BANDEIRA, G.R.L.; PINTO, H.C.S.; MAGALHÃES, P.S.; ARAGÃO, C.A.; QUEIROZ, S.O.P.; SOUZA, E.R.; SEIDO, S.L. Manejo de irrigação para cultivo de alface em ambiente protegido. Horticultura Brasileira, Brasília, v.29, n.2, p.237-241, 2011.

BASTOS, E.A.; CARDOSO, M.J.; MELO, F.B.; RIBEIRO V.Q.; ANDRADE JÚNIOR, A.S. Doses e formas de parcelamento de nitrogênio para a produção de milho sob plantio direto. Revista Ciência Agronômica, Fortaleza, v.39, n.2, p.275280, 2008.

BERNARDO, S.; SOARES, A.A.; MANTOVANI, E.C. Manual de irrigação. $8^{\circ}$.ed. Viçosa, UFV, 2008. 625p.

BROADLEY M.R.; ESCOBAR-GUTIERREZ A.J.;BURNS A.J.; BURNS I.G. What are the effects of nitrogen deficiency on growth components of lettuce. New Phytologist, Lancaster, v.147, n.3, p.519-526, 2000.

CARDOSO, G.G.G.; KLAR, A.E. Potenciais de água no solo na produção de alface, Irriga, Botucatu, v.14. n.2, p.170-179, 2009.

CEASA-MS. BOLETIM ANUAL 2010. Disponível em: www.ceasa.ms.gov.br. Acesso em 16 de outubro de 2013.

EMBRAPA. Sistema brasileiro de classificação de solos. Rio de Janeiro: Centro Nacional de Pesquisa de Solos/Embrapa Solos, 2009. 412p.

FAQUIN, V. Nutrição mineral de plantas. Lavras: ESALFAEPE, 1994. 227p.

GENUCHTEN, M.T. A Closed-form equation for predicting the hydraulic conductivity of unsaturated soils. Soil Science Society of America Journal, Madison, v.44, n.5, p.892-898, 1980.

GOMES, E.P.; OLIVEIRA, G.Q.; SCHWERZ, F.; SILVA, P.A.; BISCARO, G.A.; SANTOS, R.C. Avaliação do medidor eletrônico de umidade do solo "Hidrofarm" em Latossolo Vermelho

\section{REVENG 456-465p.}


distroférrico. Revista Brasileira de Agricultura Irrigada, Fortaleza, v.7, n.1, p.85-90, 2013.

GONÇALVES, A.O.; FAGNANI, M.A.; PERES, J.G. Efeitos da cobertura do solo com filme de polietileno azul no consumo de água da cultura da alface cultivada em estufa. Engenharia Agrícola, Jaboticabal, v.25, n.3, p.622-631, 2005.

KOETZ, M.; COELHO, G.; COSTA, C.C.C.; LIMA, E.P.; SOUZA, R.J. Efeito de doses de potássio e da freqüência de irrigação na produção da alface-americana em ambiente protegido. Engenharia Agrícola, Jaboticabal, v.26, n.3, p.730-737, 2006.

LAMAUD, E.; BRUNET, Y.; BERBIGIER, P. Radiation and water use efficiencies of two coniferous forest canopies. Physics and Chemistry of the Earth, Great Britain, v.21, n.5-6, p.361-365, 1996.

MORAES, O.; BOTREL, T.A.; DIAS, C.T.S. Efeito do uso de polímero hidroretentor no solo sobre o intervalo de irrigação na cultura da alface (Lactuca sativa L.). Engenharia Rural, Piracicaba, v. 12, n.1, p. 73-80, 2001.

OLIVEIRA, A.P; PEREIRA, E.L; BRUNO, R.L.A; ALVES, E.U.; COSTA, R.F; LEAL, F.R.F. Produção e qualidade fisiológica de sementes de feijão-vagem em função de fontes e doses de nitrogênio. Revista Brasileira de Sementes, Pelotas, v.25, n.1, p.49-55, 2003.

OLIVEIRA, R.A.; REZENDE, L.S.; MARTINEZ, M.A.; MIRANDA, G.V. Influência de um polímero hidroabsorvente sobre a retenção de água no solo. Revista Brasileira de Engenharia Agrícola e Ambiental, Campina Grande, v.8, n.1, p.160-163, 2004.

PREVEDELLO, C.L.; LOYOLA, J.M.T. Efeito de polímeros hidroretentores na infiltração da água no solo. Scientia Agraria, Curitiba, v.8, n.3, p.313317, 2007.
RESENDE, G.M.; ALVARENGA, M.A.R.; YURI, J.E.; MOTA, J. H.; SOUZA, R.J.; RODRIGUES JÙNIOR, J.C. Produtividade e qualidade póscolheita da alface americana em função de doses de nitrogênio e molibdênio. Horticultura Brasileira, Brasília, v.23, n.4, p.976-981, 2005.

RESENDE, G.M.; ALVARENGA, M.A.R.; YURI, J.E.; SOUZA, R.J. Rendimento e teores de macronutrientes em alface americana em função de doses de nitrogênio e molibdênio. Horticultura Brasileira, Brasília, v.30, n.3, p.373-378, 2012.

SANTANA, C.V.S.; ALMEIDA, A.C.; TURCO, S.H.N. Desempenho de cultivares de alface americana em ambientes sombreados na região do submédio São Francisco-BA. Revista Caatinga, Mossoró, v.22, n.4, p.60-64, 2009.

SOUZA, E.A.; COELHO, E.F.; PAZ, V.P.S.; COELHO FILHO, M.A. Crescimento e produtividade do mamoeiro fertirrigado com fósforo por gotejamento superficial e subsuperficial. Revista Brasileira de Fruticultura, Jaboticabal, v.27, n.3, p.495-499, 2005.

VIEIRA, T.A.; SANTANA, M.J.; VASCONCELOS, R.F.; BIUCHI, P.V. Métodos de manejo da irrigação no cultivo da alface americana. In: SEMINÁRIO DE INICIAÇÃO CIENTÍFICA DO CEFET, 1., 2008, Uberaba. Anais... Uberaba: Instituto Federal do Triangulo Mineiro, 2008. p.2125.

VILLAS BOAS, R.L.; KANO, C.; LIMA, C.P.; NANETTI, F.A.; FERNANDES. D.M. Efeito de doses de nitrogênio aplicado de forma convencional e através da fertirrigação na cultura do pimentão. Horticultura Brasileira, Brasília, v.18, suplemento, p.801-802, 2000.

WANG, Y.T.; BOOGHER, C.A. Effect of a medium-incorporatel hydrogel on plant growth and water use of two foliage species. Journal of Environment Horticulture, Washington, v.5, n.3, p.125-127, 1987. 